\title{
BMJ Open From hospitalisation to primary care: integrative model of clinical pharmacy with patients implanted with a PICC line - research protocol for a prospective before-after study
}

To cite: Pouget AM,

Civade E, Cestac P, et al. From hospitalisation to primary care: integrative model of clinical pharmacy with patients implanted with a PICC line-research protocol for a prospective before-after study. BMJ Open 2021;11:e039490. doi:10.1136/ bmjopen-2020-039490

- Prepublication history and additional supplemental material for this paper is available online. To view these files, please visit the journal online (http://dx.doi. org/10.1136/bmjopen-2020039490).

Received 16 April 2020 Revised 10 March 2021 Accepted 16 March 2021

Check for updates

(c) Author(s) (or their employer(s)) 2021. Re-use permitted under CC BY-NC. No commercial re-use. See rights and permissions. Published by BMJ.

${ }^{1}$ Department of Pharmacy, University Hospital Centre Toulouse, Toulouse, Occitanie, France

${ }^{2}$ INSERM unit 1048, I2MC,

Toulouse, Occitanie, France

Correspondence to

Alix Marie Pouget;

pouget.am@chu-toulouse.fr

\section{ABSTRACT}

Introduction Clinical pharmacy improves patient safety and secures drug management using information, education and good clinical practices. However, medical device management is still unexplored, and proof of effectiveness is needed. A PICC line (peripherally inserted central catheter) is a medical device for infusion. It accesses the central venous system after being implanted in a peripheral vein. However, complications after implantation often interfere with smooth execution of the treatment. We hypothesise that clinical pharmacy for medical devices could be as effective as clinical pharmacy for medications. The main objective is to assess the effectiveness of clinical pharmacy activities on the complication rate after PICC line implantation.

Methods and analysis This is a before-after prospective study. The study will begin with an observational period without clinical pharmacy activities, followed by an interventional period where pharmacists will intervene on drug and medical device management and provide personalised follow-up and advice. Sixty-nine adult patients will be recruited in each 6-month period from all traditional care units. The main inclusion criteria will be the implantation of a PICC line. The primary outcome is the decrease in the number of complications per patient and per month. Secondary outcomes are the consultation and hospital readmission rates, the acceptance rate of pharmaceutical interventions, the patients' quality of life, the direct hospital induced or avoided costs and the participants' satisfaction. Data will be collected using case report forms during hospitalisation and telephone follow-up after discharge. The analysis will compare these criteria during the two periods. Ethics and dissemination The study has received the approval of our Ethics Committee (Clermont-Ferrand Southeast VI, France, number AU1586). Results will be made available to the patients or their caregivers, the sponsor and other researchers when asked, as described in the consent form.

Trial registration number NCT04359056.

\section{INTRODUCTION}

Clinical pharmacy is a patient-centred health discipline whose practice aims to optimise
Strengths and limitations of this study

- This is the first study to assess the effectiveness of clinical pharmacy interventions for medical devices.

- As a primary objective, strong clinical criteria will be evaluated by measuring skin redness or fever (as signs of an infection), oedema, thrombosis and pain.

- This study proposes an integrative model of clinical pharmacy, from hospitalisation to primary care.

- The main limitations of this study are the lack of randomisation and the lack of blinding for patients and healthcare professionals.

therapy at each stage of the care pathway. Clinical pharmacy actions contribute to patient safety and the relevant and efficient use of health products. ${ }^{1}$ To ensure health products are used in a safe and appropriate manner, pharmacists analyse physicians' orders to identify errors or potentially inappropriate prescriptions based on guidelines and evidence-based medicine. Moreover, they optimise drug intake, inform patients and caregivers, organise the discharge to primary care and disseminate clinical good practices. Pharmacists also focus on patient education, information and training for healthcare professionals.

Regarding medication approaches, the effectiveness of clinical pharmacy is well known. Several clinical studies have demonstrated significant impacts on rehospitalisations, ${ }^{2-5}$ drug management ${ }^{6}$ and treatment compliance, ${ }^{7}$ patients' quality of life ${ }^{8}$ as well as a decrease of iatrogenic risk. ${ }^{9-12}$ However, studies on clinical pharmacy in the context of medical devices (MDs) are rare. ${ }^{13}$ To our knowledge, no study has described the clinical impact of a pharmacist's intervention when an MD is implanted in patients. Only 
one recent article refers to clinical pharmacy in dressings for complex wounds. ${ }^{14}$ The need for further clinical studies is undeniable.

MD classification is based on their risk of invasiveness and duration of use. Infusion equipment, such as catheters, can induce iatrogenic events, especially infections. ${ }^{15} 16$ Peripherally inserted central catheters (PICC lines) are associated with numerous clinical (eg, infections ${ }^{17}$ ) and mechanical complications (eg, catheter occlusions) ${ }^{18-27}$ PICC lines are useful for the administration of irritating products or for the repeated collection of blood samples. PICC lines are recommended when the duration of catheterisation ranges from 7 days to 3 months. ${ }^{28}$ PICC line implantations are carried out in the interventional radiology operating room.

Our working hypothesis is that clinical pharmacy interventions will prevent clinical and mechanical complications and thereby reduce hospital costs. ${ }^{29}$ Reducing complications could also prevent its consequences such as rehospitalisations ${ }^{30}$ and physician visits.

\section{METHODS AND ANALYSIS}

A scientific committee (selected by the Research and Innovation Board of the Toulouse University Hospital) composed of scientific and methodological experts and statisticians oversaw the feasibility and methodology of the study. This committee ensures the quality and relevance of the research organisation. The study procedures and assessments comply with the Standard Protocol Items: Recommendations for Interventional Trials ${ }^{31}$ checklist.

\section{Design}

A pragmatic single-centre design is used. This is a beforeafter prospective study with two consecutive phases: observational (no clinical pharmacy activities) and interventional (execution of clinical pharmacy activities and logistics optimisation). Randomisation of patients is not possible in this study due to the high risk of contamination bias. Once the clinical pharmacist arrives in the care unit, he or she should address any medical apprehension by the PICC prescribers and nurses, explaining good clinical use, affecting all the future study patients, even the control group. This is an open study. Due to the nature of the pharmaceutical interventions, blinding is not possible for patients and care providers.

\section{Setting}

The study will take place in the Toulouse University Hospital Center. Every PICC line prescription will be picked up in the interventional radiology unit, and patients will be screened for eligibility. Patients will be recruited from their hospital ward prior to the PICC line insertion. All selected participants will be asked to read and sign a consent form (online supplemental file). Each phase (observational and interventional)

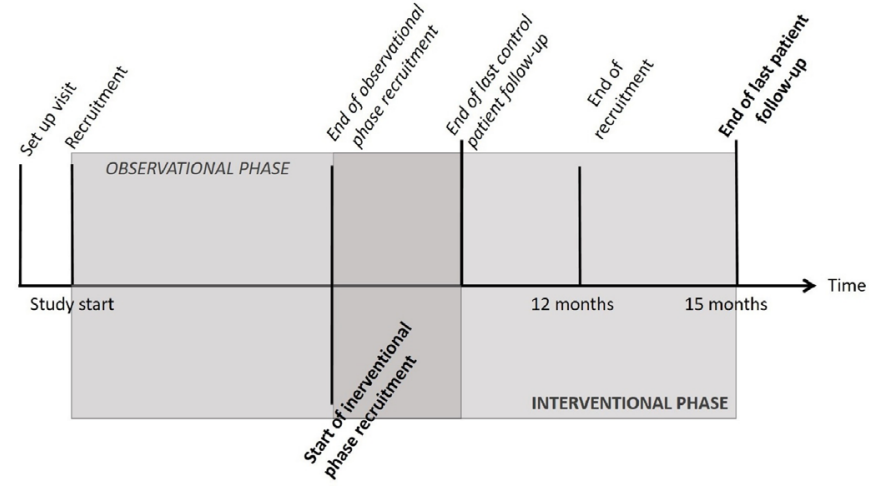

Figure 1 Study design.

will last approximately 9 months taking into account recruitment and patient follow-up. See figure 1 for the study timeline.

Recruitment began on Monday, 25 May 2020 and will end 1 year later on 25 May 2021. The study is scheduled to end on 25 August 2021.

Characteristics of participants: inclusion and exclusion criteria Eligibility criteria are listed in table 1. For all included patients, the Charlson Comorbidity Index ${ }^{32}$ will be used to assess the degree of comorbidity at baseline.

\begin{tabular}{|c|c|}
\hline \multirow{8}{*}{$\begin{array}{l}\text { Inclusion } \\
\text { criteria }\end{array}$} & Adult patient, 18 years of age or older. \\
\hline & $\begin{array}{l}\text { Patient capable of giving free and informed } \\
\text { consent. }\end{array}$ \\
\hline & $\begin{array}{l}\text { Patient insured by the Social Security System in } \\
\text { France. }\end{array}$ \\
\hline & Patient living at home. \\
\hline & Patient with a PICC line prescription. \\
\hline & $\begin{array}{l}\text { Patient whose discharge prescription should } \\
\text { contain drugs and MDs. }\end{array}$ \\
\hline & $\begin{array}{l}\text { Patient for home discharge implanted with a PICC } \\
\text { line. }\end{array}$ \\
\hline & Patient reachable by phone. \\
\hline \multirow{11}{*}{$\begin{array}{l}\text { Exclusion } \\
\text { criteria }\end{array}$} & Under-aged patient, less than 18 years old. \\
\hline & $\begin{array}{l}\text { Patient not insurance by the Social Security } \\
\text { System in France. }\end{array}$ \\
\hline & Patient not living at home: \\
\hline & Institutionalized patient. \\
\hline & $\begin{array}{l}\text { Patient living in a facility for elderly dependent } \\
\text { persons. }\end{array}$ \\
\hline & Nursing home resident. \\
\hline & 'Hospital at Home' patient. \\
\hline & $\begin{array}{l}\text { Patient deprived of their freedom by a judicial or } \\
\text { administrative decision. }\end{array}$ \\
\hline & $\begin{array}{l}\text { Patient under guardianship, curatorship or } \\
\text { safeguard of justice. }\end{array}$ \\
\hline & Patient unreachable by phone. \\
\hline & Pregnant or breastfeeding women. \\
\hline
\end{tabular}

MDs, medical devices; PICC, peripherally inserted central catheter. 
Patient and public involvement

No patient involved.

\section{Process}

Regardless of the phase of the study, the occurrence of complications due to the PICC line will be recorded during hospitalisation and at home during a follow-up phone call. Patients are monitored for the entire duration of the PICC line implantation or for a maximum of 3 months. Data will be collected at days 3 and 7 (D3 or D7, respectively) after implantation and then after 1, 2 and 3 months (M1, M2 and M3, respectively).

The control period corresponds to usual care and represents the observational phase, where no pharmaceutic interventions will be done, unless necessary for the patient's safety (eg, life-threatening situations ${ }^{33}$ ).

One participant can be included in only one phase. The interventional phase will start when the last patient is included in the observational phase. Physicians and nurses, as well as other healthcare professionals, will attend training sessions on updates, recommendations, indications and maintenance related the use of PICC lines. If necessary, training sessions will be repeated once to make sure the research team met all the healthcare professionals involved.

Two pharmacists and a pharmacy resident will participate in each phase.

The table 2 describes the research procedures and activities in the two phases.

At the end of the study, a satisfaction survey will be sent to every participant (patients and caregivers).

\section{Outcomes and expected benefits \\ Primary outcome}

The primary outcome is the number of complications per patient and per month. Complications will be documented on specific forms to harmonise data collection. Mechanical complications are defined as obstruction or occlusion, ${ }^{18}$ breakage or damage to the catheter, ${ }^{27}$ migration $^{34}$ or dislodgment (accidental withdrawal) of the catheter. ${ }^{35}$ Clinical complications are defined as redness around the insertion site (diameter $>2 \mathrm{~cm}$ ), oedema (size difference between the two hands), pain (numeric rating scale) and fever (internal temperature $>37^{\circ} \mathrm{C}$ ) as signs of an infection ${ }^{1736}$ and thrombotic events ${ }^{37}$ (confirmed by a medical modality such as echography).

\section{Secondary outcomes}

The number of consultations and rehospitalisations postdischarge will be used to determine the clinical impact beyond the initial hospitalisation. ${ }^{11}$ 38-40 The expected result is a decrease in the consultation and rehospitalisation rates at the end of the intervention phase compared with the observation phase.

The acceptance rate of pharmaceutical interventions during the interventional phase is used to assess the appropriateness of pharmaceutical interventions. ${ }^{41-45}$ A higher acceptance rate means the pharmaceutical interventions are justified and relevant to the care providers. The criticality of the pharmacist's intervention ${ }^{46}$ will be evaluated. Moreover, conformity of the hospital prescriptions for primary care after the discharge will be assessed. The aim is to avoid treatment breaks.

Another secondary outcome involves the conformity analysis of the PICC line logistics circuit (checklist related to stock, supply chain and traceability). Management of the hospital supply chain is a major financial challenge ${ }^{47}$ and generally leads to decreased treatment risk and costs. ${ }^{48}$ The objective is to streamline the various stages of the PICC line logistics circuit, from ordering to implantation. By streamlining the logistics, improved patient safety and reduced costs are expected.

The conformity of the PICC line indication will be evaluated according to recommendations. ${ }^{49}$ Prescriptions too often seem to be trivialised and little guided by attending doctors. Therefore, errors are possible. The aim is to improve the team's knowledge and the communication between hospital units.

The patients' quality of life before and after the follow-up will be measured with the EQ-5D-5L questionnaire. ${ }^{50}$ As previously described by Andrade et $a l^{51}$ a standard value set for converting the profiles on the five dimensions onto a score will be used.

An improvement in the quality of life score is expected during the intervention phase.

Satisfaction of the patients and the healthcare providers involved will be evaluated. To develop clinical pharmacy activities in healthcare services, collaboration and communication with healthcare teams is essential.

The direct hospital costs will be estimated and described. The objective is to estimate whether additional costs are induced or whether costs are spared through better organisation and logistics management. ${ }^{52}$

\section{Statistical analysis}

Sample size calculation

According to the ENEIS studies (2004 and 2009) and their final report, ${ }^{53}$ at least $50 \%$ of iatrogenic serious adverse events are preventable whether due to medications or MDs. Assuming that clinical pharmacy integration could theoretically lead to a $25 \%$ decrease in the complication rate during the interventional phase, 62 patients are needed in each group ( $80 \%$ power, alpha $5 \%$ ). Thus, 138 patients need to be recruited assuming that $10 \%$ are lost to follow-up. All early exits from the study will be considered as lost to follow-up, and the affected data will be processed in the statistical analysis as intent to treat.

\section{Statistics}

Statistical tests will be used that are appropriate for the distribution of the variables. All tests will be performed at an alpha risk of $5 \%$. Categorical variables will be described by counts and percentages. Means and SD will be reported for continuous variables with normal distribution, and median and quartiles for other continuous variables. 
Table 2 Detailed research process

\begin{tabular}{|c|c|c|c|}
\hline Timepoint & Research steps & Observational phase & Interventional phase \\
\hline \multirow[t]{15}{*}{ Hospitalisation } & $\begin{array}{l}\text { PICC line } \\
\text { prescription }\end{array}$ & \multicolumn{2}{|c|}{ Screening: eligibility assessment } \\
\hline & $\begin{array}{l}\text { Intervention } \\
\text { scheduled }\end{array}$ & \multicolumn{2}{|c|}{ Enrolment: informed consent } \\
\hline & PICC line & \multicolumn{2}{|c|}{ Document purpose and duration of catheterisation } \\
\hline & & & $\begin{array}{l}\text { Pharmaceutical analysis to identify errors or potentially inappropriate } \\
\text { prescriptions*; discussion with prescribers; pharmaceutical interventions in the } \\
\text { event of unjustified deviation from existing guidelines. }\end{array}$ \\
\hline & In the operating & \multicolumn{2}{|c|}{ Verify that all necessary equipment is available for the surgery. } \\
\hline & $\begin{array}{l}\text { room (UR) betore } \\
\text { the implantation }\end{array}$ & & Help with ordering if necessary. \\
\hline & & \multicolumn{2}{|c|}{ Conformity assessment of the expiration date for all PICC lines stored in the OR's supply room. } \\
\hline & & & $\begin{array}{l}\text { Help with ordering if necessary. Rationalisation of the medical device stock if } \\
\text { necessary. }\end{array}$ \\
\hline & & \multicolumn{2}{|c|}{$\begin{array}{l}\text { Conformity assessment of traceability from receipt of the medical device order by the pharmacy to } \\
\text { delivery to the care unit. }\end{array}$} \\
\hline & & & Corrections if necessary. \\
\hline & Implantation of & \multicolumn{2}{|c|}{ Number of medical devices used during the operation (implantation failures or non-functional devices). } \\
\hline & PICC IIne=day 0 & \multicolumn{2}{|c|}{$\begin{array}{l}\text { Implantation traceability to ensure lot numbers match in the patient's record, the OR book and the } \\
\text { computer software. }\end{array}$} \\
\hline & & & Corrections if necessary. \\
\hline & Remainder of the & \multicolumn{2}{|c|}{ Record possible complications during the remainder of the hospital stay. } \\
\hline & hospitalısatıon & \multicolumn{2}{|r|}{ Corrections and help if complications occur. } \\
\hline \multirow[t]{4}{*}{ Discharge } & $\begin{array}{l}\text { Discharge } \\
\text { prescription }\end{array}$ & \multicolumn{2}{|c|}{$\begin{array}{l}\text { Pharmaceutical analysis of the patient's discharge order. The analysis will focus on drugs and MDs } \\
\text { related to the PICC line (eg, dressing repair set). } \\
\text { Conformity analysis of the hospital prescriptions issued by local pharmacy. }\end{array}$} \\
\hline & & & $\begin{array}{l}\text { Pharmaceutical analysis of the patient's discharge order and optimisation* if } \\
\text { necessary. Discussion with the physician and correction. }\end{array}$ \\
\hline & Patient discharge & \multicolumn{2}{|c|}{ Quality of life assessment (EQ-5D-5L scale). } \\
\hline & & & $\begin{array}{l}\text { Pharmaceutical interview with the patient: } \\
\text { Discuss the different treatments on the discharge order, answer any questions. } \\
\text { Provide information about the PICC line, how to use it, maintain it and how to } \\
\text { detect potential complications. } \\
\text { Make sure that traceability documents are provided. } \\
\text { Make sure that the PICC line's user booklet is provided. } \\
\text { Transmission of the discharge order to the community pharmacist. }\end{array}$ \\
\hline \multirow[t]{5}{*}{ Primary care } & $\begin{array}{l}\text { Day } 3 \\
\text { Day } 7\end{array}$ & \multicolumn{2}{|c|}{$\begin{array}{l}\text { Phone calls to collect complications or any events regarding the PICC line and drugs } \\
\text { Patient. } \\
\text { Private nurse. }\end{array}$} \\
\hline & & & $\begin{array}{l}\text { Provide personalised and appropriate advice. } \\
\text { Pharmaceutical interventions if necessary. }\end{array}$ \\
\hline & $M 1, M 2$ & \multicolumn{2}{|c|}{$\begin{array}{l}\text { Phone calls to collect complications or any events regarding the PICC line and drugs: } \\
\text { Patient. } \\
\text { Phone calls to community pharmacist to record information related to care consumption. } \\
\text { Private nure. }\end{array}$} \\
\hline & & \multicolumn{2}{|r|}{$\begin{array}{l}\text { Provide personalised and appropriate advice. } \\
\text { Pharmaceutical interventions if necessary. }\end{array}$} \\
\hline & M3 & \multicolumn{2}{|c|}{$\begin{array}{l}\text { Quality of life assessment (EQ-5D-5L scale). } \\
\text { Phone calls to collect complications or any events regarding the PICC line and drugs: } \\
\text { Patient. } \\
\text { Private nurse. } \\
\text { Community pharmacist to record information related to care consumption. } \\
\text { General practitioner to identify any consultations related to the PICC line and any other relevant } \\
\text { information. } \\
\text { Sooner if there is a need to confirm clinical data on complications such as thrombotic events. }\end{array}$} \\
\hline
\end{tabular}


Table 3 Statistical analysis for the secondary outcomes

\begin{tabular}{llll}
\hline Variables types & Variables of interest & Description* & \multicolumn{1}{c}{ Tests* } \\
\hline Quantitative & Consultations and rehospitalisations after & Means \pm SD or medians and & \multicolumn{1}{c}{ Student's t-test } \\
& discharge. & quartiles. & or non-parametric \\
& EQ-5D-5L scores. & Frequency table. & Wilcoxon's test. \\
Qualitative & Direct hospital costs. & & Frequency table. \\
& $\begin{array}{l}\text { implantation and prescriptions issued by local } \\
\text { pharmacy). }\end{array}$ & & $\chi^{2}$ test or Fisher's \\
& Satisfaction levels. & & \\
\hline
\end{tabular}

${ }^{*}$ According to the distribution of variables.

Patient demographics and clinical characteristics will be described.

To assess the effectiveness of the intervention, means or medians of the number of complications per month and per patient for each phase will be estimated, and a Poisson regression will be used. An adjustment for confounding factors such as sex, age and Charlson Comorbidity Index is planned.

The secondary outcomes will be analysed as described in table 3.

\section{DISCUSSION}

The main objective is to demonstrate the effectiveness of clinical pharmacy activities in preventing complications in patients implanted with a PICC line. This is a strong clinical criterion. There is abundant literature about the occurrence of complications following the insertion of a PICC line, in a hospital ${ }^{20-24}$ or at home. ${ }^{275455}$ At the same time, reported rates vary widely across studies. These rates were pooled to estimate an 'average' complication rate. This method was used to calculate the number of subjects needed for this study. These assumptions have an impact on the robustness of the study and may require the use of statistical adjustments when analysing the results. As for complications, the numbers of consultations and rehospitalisations postdischarge have been used in several studies, particularly the 30-day readmission rate e $^{11} 40$ 56-58 to assess the clinical effectiveness of a pharmacist's interventions. Despite the wide assortment of these rates in the literature, this indicator is relevant for comparing our study with others. However, it will be difficult to obtain exhaustive results, as the data will be derived from statements made by the different participants. The information will only be formally verifiable if the patient in question is readmitted or consults in one of our hospital's departments.

The acceptance rate of pharmaceutical interventions is a widely used and recognised indicator ${ }^{41}{ }^{59}$ for assessing the appropriateness of interventions and an indicator routinely used in hospitals. A conformity analysis of the hospital prescriptions for primary care is one of the secondary endpoints. It seems essential to secure these prescriptions also because the patient's transition is known to be a high risk event. ${ }^{60}$ Good clinical practices allow health professionals to decrease errors and avoid potential errors in prescription. Iatrogenic events are associated with additional costs. ${ }^{61}$ A checklist of items was developed to evaluate the conformity of the PICC line's logistics circuit. This list is particularly exhaustive and will be used by all those who collect data. This will avoid an evaluation bias that could be linked to the large number of healthcare providers involved. The checklist will help to identify the most common errors or pitfalls encountered and to establish adequate corrective measures. Current guidelines are available for the device's logistics. ${ }^{49}$

The prospective study design allows to assess the patients' quality of life using the EQ-5D-5L Scale before and after the intervention. This criterion is needed to assess the patient's point of view, as the patient is the central element in the care pathway. To avoid interference or influence due to the presence of pharmacists, they will not to be present at the time of the first evaluation (day of discharge). However, the subsequent assessments will be done by telephone, thus pharmacists could influence patient responses. Likert scales have been developed to collect patient and healthcare professional satisfaction data. ${ }^{62}$ These tools are valid and reliable for collecting the opinions of different research participants. These scales capture more nuanced opinions, help to better understand the feedback and to identify areas for improvement. The various parties involved generally appreciate these tools. It should not be particularly difficult to collect and analyse these results. Nevertheless, different patients will be enrolled during the observational and interventional phases. Consequently, the differences in satisfaction, if any, may also be due to a difference in individuals between the two groups. A low response rate from professionals to the satisfaction survey is expected, as described in the literature. ${ }^{63}$

This study involves only one hospital and focuses on one type of implantation. This is a preliminary study before scaling up a larger, multicentre and randomised trial with several implantable medical devices (IMDs). This future study will follow a stepped-wedge method consisting of randomisation by centre and not by patient for the deployment of before-and-after phases in each of the participating centres. This study is a major step towards evaluating the efficacy of clinical pharmacy 
applied to IMDs with the aim of a larger scale study with valuable randomisation. At this moment, the before-after design appears to be the closest to the stepped-wedge method since they share separate observational and interventional periods. Indeed, randomisation is not possible given the nature of the intervention and the high risk of contamination bias. This point is critical. Moreover, the measurement and analysis of costs is limited to direct hospital medical costs, which does not allow an overall analysis of the costs of care. Additional health economics analyses are planned for the multicentre study.

This study will investigate the impact of the integration of clinical pharmacy activities during the overall care pathway. This is the first step towards a change in practices, improved communication between professionals, better collaboration and the integration of a clinical pharmacist into multidisciplinary teams, including surgical ones. This study is the first, to our knowledge, to focus on clinical pharmacy for implantable MDs with a hard, clinical endpoint.

\section{Potential limitations and bias}

Since the study is not randomised, the selection bias and two non-comparable samples are risky. To overcome this limitation, an adjustment on the main confounding factors (such as age, sex and comorbidity index) will be considered.

Blinding is not possible due to the nature of the intervention. To limit a measurement bias, a blind methodologist will analyse the primary endpoint.

Recruitment may take longer than expected because all the PICC lines are placed in the operating room and are not a priority as opposed to life-threatening emergencies.

Phone calls to collect clinical data on complications, deaths and rehospitalisations are limited. The collected data are based solely on the patients' and care providers' statements. It is possible that they may intentionally or unintentionally omit some information. The plurality of involved counterparts may help to corroborate the given information. Data collection will be harmonised by double-checking the collection forms and the information collected at the time of the pharmaceutical interviews and phone calls.

\section{Trial status}

Recruiting since 25 May 2020.

National registration number: 2019-A02475-52.

\section{Ethics and dissemination}

The regional French Ethics Committee (CPP South-East VI, Clermont-Ferrand, France) assessed the scientific ethics of the protocol (version dated 3 February 2020) and approved this study.

All data collected will be anonymised, and access to the data will be restricted to those participating in the research (investigators, pharmacists and pharmacy residents).

The results of the study will be published when available.
Acknowledgements The authors would like to thank the Foundation for Hospital Research and the French Society of Clinical Pharmacy for choosing this project to be developed and the financial help provided.

Contributors AMP, EC and CR-L contributed to the conception of the study. The authors will be responsible for the acquisition and analysis of the data, interpretation and dissemination of the results. AMP and CR-L contributed to the draft of this protocol. All authors contributed to the revision of this protocol and approved the final version to be published. All authors have agreed to be accountable for all aspects of the study such as accuracy and integrity of the work.

Funding The Research and Innovation Board of the Toulouse University Hospital Centre is the sponsor of this study. The protocol is locally registered with the following number: RC31/18/0459. This work is supported by a grant from the Foundation for Hospital Pharmacy Research and the French Society of Clinical Pharmacy (Call for Projects, November 2018).

Competing interests None declared.

Patient consent for publication Not required.

Provenance and peer review Not commissioned; externally peer reviewed.

Supplemental material This content has been supplied by the author(s). It has not been vetted by BMJ Publishing Group Limited (BMJ) and may not have been peer-reviewed. Any opinions or recommendations discussed are solely those of the author(s) and are not endorsed by BMJ. BMJ disclaims all liability and responsibility arising from any reliance placed on the content. Where the content includes any translated material, BMJ does not warrant the accuracy and reliability of the translations (including but not limited to local regulations, clinical guidelines, terminology, drug names and drug dosages), and is not responsible for any error and/or omissions arising from translation and adaptation or otherwise.

Open access This is an open access article distributed in accordance with the Creative Commons Attribution Non Commercial (CC BY-NC 4.0) license, which permits others to distribute, remix, adapt, build upon this work non-commercially, and license their derivative works on different terms, provided the original work is properly cited, appropriate credit is given, any changes made indicated, and the use is non-commercial. See: http://creativecommons.org/licenses/by-nc/4.0/.

ORCID iD

Alix Marie Pouget http://orcid.org/0000-0002-2379-454X

\section{REFERENCES}

1 Société Française de Pharmacie Clinique (SFPC). Présentation de la Pharmacie Clinique [Internet], 2016. Available: http://sfpc.eu/fr/lasfpc/presentation.html

2 Jack BW, Chetty VK, Anthony D, et al. A reengineered hospital discharge program to decrease rehospitalization: a randomized trial. Ann Intern Med 2009;150:178-87.

3 Pal A, Babbott S, Wilkinson ST. Can the targeted use of a discharge pharmacist significantly decrease 30-day readmissions? Hosp Pharm 2013;48:380-8.

4 McKay C, Park C, Chang J, et al. Systematic review and metaanalysis of pharmacist-led transitions of care services on the 30-day all-cause readmission rate of patients with congestive heart failure. Clin Drug Investig 2019;39:703-12.

5 Renaudin P, Boyer L, Esteve M-A, et al. Do pharmacist-led medication reviews in hospitals help reduce hospital readmissions? A systematic review and meta-analysis. $\mathrm{Br} J$ Clin Pharmacol 2016;82:1660-73.

6 Haute Autorité de Santé - Mettre en œuvre la conciliation des traitements médicamenteux en établissement de santé [Internet].. Available: https://www.has-sante.fr/jcms/c 2736453/fr/mettreen-oeuvre-la-conciliation-des-traitements-medicamenteux-enetablissement-de-sante

7 Lipton HL, Bird JA. The Impact of Clinical Pharmacists' Consultations on Geriatric Patients' Compliance and Medical Care Use: A Randomized Controlled Trial. Gerontologist 1994;34:307-15.

8 Sadik A, Yousif M, McElnay JC. Pharmaceutical care of patients with heart failure. Br J Clin Pharmacol 2005;60:183-93.

9 Leguelinel-Blache G, Arnaud F, Bouvet S, et al. Impact of admission medication reconciliation performed by clinical pharmacists on medication safety. Eur J Intern Med 2014;25:808-14.

10 Lehnbom EC, Stewart MJ, Manias E, et al. Impact of medication reconciliation and review on clinical outcomes. Ann Pharmacother 2014;48:1298-312.

11 Mekonnen AB, McLachlan AJ, Brien J-AE. Effectiveness of pharmacist-led medication reconciliation programmes on clinical 
outcomes at hospital transitions: a systematic review and metaanalysis. BMJ Open 2016;6:e010003.

12 Daliri S, Hugtenburg JG, Ter Riet G, et al. The effect of a pharmacyled transitional care program on medication-related problems post-discharge: a before-after prospective study. PLOS One 2019;14:e0213593.

13 Ferrand É., Painchart L, Grimandi G, et al. Rôles et retombées des pharmaciens dans la gestion des dispositifs médicaux en établissement de santé : une revue de littérature. Ann Pharm Fr 2017;75:409-19.

14 Painchart L, Drancourt P, Aubert J, et al. [Interest and difficulties in setting up pharmaceutical reconciliations for patients with dressings for complex wounds]. Ann Pharm Fr 2019;77:516-31.

15 Kumar A, Kethireddy S, Darovic GO. Catheter-related and infusionrelated sepsis. Crit Care Clin 2013;29:989-1015.

16 Rupp ME, Karnatak R. Intravascular catheter-related bloodstream infections. Infect Dis Clin North Am 2018;32:765-87.

17 Lee JH, Kim ET, Shim DJ, et al. Prevalence and predictors of peripherally inserted central catheter-associated bloodstream infections in adults: a multicenter cohort study. PLoS One 2019;14:e0213555

18 Bartock L. An evidence-based systematic review of literature for the reduction of PICC line occlusions. J Assoc Vasc Access 2010;15:58-63

19 Grove JR, Pevec WC. Venous thrombosis related to peripherally inserted central catheters. J Vasc Interv Radiol 2000;11:837-40.

20 Cowl CT, Weinstock JV, Al-Jurf A, et al. Complications and cost associated with parenteral nutrition delivered to hospitalized patients through either subclavian or peripherally-inserted central catheters. Clin Nutr 2000;19:237-43.

21 Amerasekera SSH, Jones CM, Patel R, et al. Imaging of the complications of peripherally inserted central venous catheters. Clin Radiol 2009;64:832-40.

22 Leroyer C, Lashéras A, Marie V, et al. Prospective follow-up of complications related to peripherally inserted central catheters. Med Mal Infect 2013;43:350-5.

23 Greene MT, Flanders SA, Woller SC, et al. The association between PICC use and venous thromboembolism in upper and lower extremities. Am J Med 2015;128:986-93.

24 Bertoglio S, Faccini B, Lalli L, et al. Peripherally inserted central catheters (PICCs) in cancer patients under chemotherapy: a prospective study on the incidence of complications and overall failures. J Surg Oncol 2016;113:708-14.

25 Jones D, Wismayer K, Bozas G, et al. The risk of venous thromboembolism associated with peripherally inserted central catheters in ambulant cancer patients. Thromb J 2017;15:1-6.

26 Grau D, Clarivet B, Lotthé A, et al. Complications with peripherally inserted central catheters (PICCs) used in hospitalized patients and outpatients: a prospective cohort study. Antimicrob Resist Infect Control 2017;6:1-8.

27 Opilla M. Peripherally inserted central catheter experience in long-term home parenteral nutrition patients. J Assoc Vasc Access 2017;22:42-5.

28 Société Française d'Hygiène Hospitalière (SF2H). Bonnes Pratiques Et Gestion Des Risques Associés Au Picc -Hygiènes -Volume Xxi - $\mathrm{N}^{\circ}$ 6., 2013. Available: https://sf2h.net/wp-content/uploads/2014/05/ SF2H_bonnes-pratiques-et-gestion-des-risques-associes-au-PICC2013.pdf

29 Gallagher J, McCarthy S, Byrne S. Economic evaluations of clinical pharmacist interventions on hospital inpatients: a systematic review of recent literature. Int J Clin Pharm 2014;36:1101-14.

30 Lawson EH, Hall BL, Louie R, et al. Association between occurrence of a postoperative complication and readmission: implications for quality improvement and cost savings. Ann Surg 2013;258:10-18.

31 Chan A-W, Tetzlaff JM, Altman DG, et al. SPIRIT 2013 statement: defining standard protocol items for clinical trials. Ann Intern Med 2013;158:200-7.

32 Charlson ME, Pompei P, Ales KL, et al. A new method of classifying prognostic comorbidity in longitudinal studies: development and validation. J Chronic Dis 1987:40:373-83.

33 Dale MA, Copeland R, Barton R. Prescribing errors on medical wards and the impact of clinical pharmacists. Int $\mathrm{J}$ Pharm Pract 2010;11:19-24.

34 Haygood TM, Malhotra K, Ng C, et al. Migration of central lines from the superior vena cava to the Azygous vein. Clin Radiol 2012;67:49-54.

35 Moureau N. Impact and safety associated with accidental Dislodgement of vascular access devices: a survey of professions, settings, and devices. J Assoc Vasc Access 2018;23:203-15.

36 Chopra V, Anand S, Krein SL, et al. Bloodstream infection, venous thrombosis, and peripherally inserted central catheters: reappraising the evidence. Am J Med 2012;125:733-41. doi:10.1016/j. amjmed.2012.04.010

37 Fallouh N, McGuirk HM, Flanders SA, et al. Peripherally inserted central catheter-associated deep vein thrombosis: a narrative review. Am J Med 2015;128:722-38.

38 Unplanned hospital visits [Internet]. Available: https://www.medicare. gov/hospitalcompare/Data/Hospital-returns.html

39 Koehler BE, Richter KM, Youngblood L, et al. Reduction of 30-day postdischarge hospital readmission or emergency department (ED) visit rates in high-risk elderly medical patients through delivery of a targeted care bundle. J Hosp Med 2009;4:211-8.

40 Hohl CM, Partovi N, Ghement I, et al. Impact of early in-hospital medication review by clinical pharmacists on health services utilization. PLoS One 2017;12:e0170495

41 Bedouch P, Charpiat B, Conort O, et al. Assessment of clinical pharmacists' interventions in French hospitals: results of a multicenter study. Ann Pharmacother 2008;42:1095-103.

42 Charpiat B, Bedouch P, Conort O, et al. Opportunités d'erreurs médicamenteuses et interventions pharmaceutiques dans le cadre de la prescription informatisée : revue des données publiées par les pharmaciens hospitaliers français. Ann Pharm Fr 2012;70:62-74.

43 Charpiat $\mathrm{B}$, Conort $\mathrm{O}$, Juste $\mathrm{M}$, et al. Mise à disposition de l'outil de codification des interventions pharmaceutiques de la Société française de pharmacie clinique : bilan à 10ans et perspectives. $L e$ Pharmacien Hospitalier et Clinicien 2015;50:125-35.

44 Mongaret C, Quillet P, Vo TH, et al. Predictive factors for clinically significant pharmacist interventions at hospital admission. Medicine 2018;97:e9865

45 Aguiar KdaS, Santos JMD, Cambrussi MC, et al. Patient safety and the value of pharmaceutical intervention in a cancer Hospital. Einstein 2018:16:eAO4122.

$46 \mathrm{Ha}$ Vo T. Evaluation of the potential impact of pharmacist interventions : development and validation of the CLEO multidimensional tool [Internet]. Available: https://tel.archivesouvertes.fr/tel-01315619

47 Moons K, Waeyenbergh G, Pintelon L. Measuring the logistics performance of internal Hospital supply chains - a literature study. Omega 2019;82:205-17.

48 Chasseigne V, Leguelinel-Blache G, Nguyen TL, et al. Assessing the costs of disposable and reusable supplies wasted during surgeries. Int J Surg 2018;53:18-23. doi:10.1016/j.ijsu.2018.02.004

49 Société Française d'Hygiène Hospitalière (SF2H). Good practice and risk management for the use of PICC, 2013.

50 Redmond P, Grimes TC, McDonnell R, et al. Impact of medication reconciliation for improving transitions of care. Cochrane Database Syst Rev 2018;13.

51 Andrade LF, Ludwig K, Goni JMR, et al. A French value set for the EQ-5D-5L. Pharmacoeconomics 2020;38:413-25.

52 Chasseigne V, Bouvet S, Chkair S, et al. Health economic evaluation of a clinical pharmacist's intervention on the appropriate use of devices and cost savings: a pilot study. Int J Surg 2020;82:143-8.

53 Michel P, Lathelize M, Bru-Sonnet R, et al. Rapport final Comparaison des deux études ENEIS 2004 et 2009. Drees: Ministère la santé, 2011: 1-118.

54 Christensen LD, Holst M, Bech LF, et al. Comparison of complications associated with peripherally inserted central catheters and Hickman ${ }^{\mathrm{TM}}$ catheters in patients with intestinal failure receiving home parenteral nutrition. six-year follow up study. Clin Nutr 2016;35:912-7.

55 Santacruz E, Mateo-Lobo R, Riveiro J, et al. Infectious complications in home parenteral nutrition: a long-term study with peripherally inserted central catheters, tunneled catheters, and ports. Nutrition 2019;58:89-93.

56 Kilcup M, Schultz D, Carlson J, et al. Postdischarge pharmacist medication reconciliation: impact on readmission rates and financial savings. J Am Pharm Assoc 2013;53:78-84.

57 Jones CD, Anthony A, Klein MD, et al. The effect of a pharmacist-led multidisciplinary transitions-of-care pilot for patients at high risk of readmission. J Am Pharm Assoc 2018:58:554-60.

58 Lussier ME, Evans HJ, Wright EA, et al. The impact of community pharmacist involvement on transitions of care: a systematic review and meta-analysis. J Am Pharm Assoc 2020;60:153-62.

59 Leguelinel-Blache G, Castelli C, Roux-Marson C, et al. Impact of collaborative pharmaceutical care on in-patients' medication safety: study protocol for a stepped wedge cluster randomized trial (MEDREV study). Trials 2018;19:19.

60 Ensing HT, Stuijt CCM, van den Bemt BJF, et al. Identifying the optimal role for pharmacists in care transitions: a systematic review. J Manag Care Spec Pharm 2015;21:614-36. 
61 Rigby K, Clark RB, Runciman WB. Adverse events in health care: setting priorities based on economic evaluation. J Qual Clin Pract 1999;19:7-12.

62 Likert R. A technique for the measurement of attitudes. Arch Psychol 1932;22:55.

63 Cook JV, Dickinson HO, Eccles MP. Response rates in postal surveys of healthcare professionals between 1996 and 2005: an observational study. BMC Health Serv Res 2009;9:1-8.
64 Gallagher P, Ryan C, Byrne S, et al. STOPP (screening tool of older person's prescriptions) and start (screening tool to alert doctors to right treatment). consensus validation. Int J Clin Pharmacol Ther 2008;46:72-83.

65 Renom-Guiteras A, Meyer G, Thürmann PA. The EU(7)-PIM list: a list of potentially inappropriate medications for older people consented by experts from seven European countries. Eur J Clin Pharmacol 2015;71:861-75. 